Gravimetrisch waren $0,0916 \mathrm{~g} \mathrm{Mg}_{2} \mathrm{P}_{2} \mathrm{O}_{7}$ für $\mathrm{H}_{8} \mathrm{PO}_{2}+\mathrm{H}_{8} \mathrm{PO}_{8}$ gefunden worden, also auf $0,4 \%$ übereinstimmend. Daraus kann geschlossen werden, dass auch das jodometrisch ermittelte Quantitätsverhăltnis zwischen phosphoriger und unterphosphoriger Säure mit befriedigender Annaherung der Wirklichkeit entsprechen muss.

Es enthielten demzufolge $100 \mathrm{~g}$ jener phosphatischen Săure:

$$
\begin{gathered}
55,73 \% \mathrm{H}_{3} \mathrm{PO}_{4} \\
25,91 \cong \mathrm{H}_{8} \mathrm{PO}_{8} \\
1,70 \cong \mathrm{H}_{3} \mathrm{PO}_{2} \\
16,66 ” \mathrm{H}_{2} \mathrm{O} .
\end{gathered}
$$

Chem. Univers. -Laborat. (Phil. Abt.), Freiburg i. B.

\title{
Ueber Darstellung, Eigenschaften und Entschwefelung des Aethylenthioharnstoffes.
}

\author{
Von Apotheker Dr. H. Klut.
}

(Eingegangen den 17. XI. 1902.)

Den Aethylenthioharnstoff, welcher folgende Konstitution besitzt:

$$
\stackrel{\mathrm{CH}_{2}-\mathrm{NH}_{\mathrm{CH}}}{\mathrm{CH}_{2}-\mathrm{NH}}>\mathrm{CS}
$$

stellte zuerst A. W. Hofmann') durch Einwirkung von Schwefelkohlenstoff auf reines Aethylendiamin in alkoholischer Lösung dar. W. Schacht ${ }^{2}$ ) unterzog später das von Hofmann angegebene Verfahren zur Darstellung dieses Sulfoharnstoffes einer eingehenden Prufung, und bestätigte im allgemeinen die von letzterem gemachten Angaben. Nur fand er den Schmelzpunkt bei $197^{\circ}$, wăhrend Hofmann denselben bei $194^{\circ}$ ermittelte.

Da reines Aethylendiamin jedoch ein ziemlich kostspieliges Präparat ist, kann man vorteilhafter, wie folgt, obigen Harnstoff gewinnen.

Als Ausgangsmaterial dient hierbei das im Handel erhältliche Aethylendiamin in $10 \%$ wåsseriger Lösung, welche eine stark alkalische, schwach gelbliche Flüssigkeit bildet. Zwecks Entfernung des darin stets in geringer Menge vorhandenen Ammoniaks empfiehlt es sich, letzteres durch lăngeres Erhitzen am Rückflusskühler zu entfernen. Die davon befreite Base verwandelt man nun am besten durch Zusatz

1) Berichte d. d. chem. Ges. 5, 242.

ग) Archiv d. Pharm. 1897, 235, S. 441. 
von Salzsæure in das Hydrochlorat. Auf 1 Molekïl $\mathrm{C}_{2} \mathrm{H}_{4}\left(\mathrm{NH}_{2}\right)_{2}$ fügt man 2 Moleküle $\mathrm{HCl}$ hinzu. Die jetzt neutrale oder ganz schwach sauer reagierende klare Lösung dampft man auf dem Wasserbade zur staubigen Trockne ein. Es resultiert alsdann eine krystallinische, grauweisse Masse. Durch Umkrystallisieren aus wenig Wasser wird das salzsaure Aethylendiamin chemisch rein erhalten. Will man hieraus etwa die Base wieder isolieren, so mischt man äquivalente Mengen dieses salzsauren Salzes mit frisch getrocknetem Natriumhydroxyd und erhitzt im Glaskolben auf dem Sandbade. Bei ca. $116^{\circ}$ destilliert dann die freie Base in Form einer öligen, farblosen Flussigkeit mit noch einem Moleküle Wasser über:

$$
\stackrel{\mathrm{CH}_{2}-\mathrm{NH}_{2}}{\mathrm{CH}_{2}}+\mathrm{NH}_{2}+\mathrm{H}_{2} \mathrm{O} \text {. }
$$

Man verfährt nun behufs Darstellung des Aethylensulfoharnstoffes zweckmässig folgendermassen:

$20 \mathrm{~g}$ salzsaures Aethylendiamin löst man in $40 \mathrm{~g}$ Wasser, versetzt zur Isolierung der freien Base hieraus mit der berechneten Menge Natriumhydroxydes. Nach Lösung des letzteren fügt man zur Fällung des gebildeten Chlornatriums $350 \mathrm{~g}$ Alkohol hinzu und lässt über Nacht stehen. Das Natriumchlorid hat sich in dieser Zeit gut am Boden des Glaskolbens abgesetzt. Man behandelt nun das klare Filtrat nach der von Hofmann angegebenen Vorschrift weiter. Jedoch möchte ich nicht unerwähnt lassen, dass man zur Erlangung einer quantitativen Ausbeute an diesem Harnstoff in dem Schwefelkohlenstoff vorher eine Spur elementaren Schwefel löst. Der Alkohol lässt sich für spätere Darstellangen durch Abdestillieren ganz gut wieder verwenden. Man reinigt diesen Thioharnst off am besten durch Umkrystallisieren aus warmem Wasser. Bei höherer Temperatur dieses Lősungsmittels zersetzt sich letzterer schion partiell. So gewonnen, schmilzt derselbe, wie Hotmann angiebt, bei $194^{\circ}$ glatt.

Der Aethylenthioharnstoff zeichnet sich durch Leichtlöslichkeit in Wasser aus. In Alkohol ist er schwer löslich. Man gewinnt ihn hieraus beim Verdunsten des Alkohols in fächerartig verzweigten Nadeln. Aus Amylalkobol krystallisiert er in rhombischen Prismen. In Aether, Chloroform, Benzol und Ligroin ist er nicht löslich.

Der in dem Aethylenthioharnstoffe vorhandene Schwefel ist äusserst fest gebunden, und es gelingt nur sehr schwer, denselben durch ein Sauerstoffatom zu substituieren. Schon $H$ of $\operatorname{man}^{1}$ ) fand, dass diese Verbindung eine sebr bemerkenswerte Stabilitat zeigte. Alle Versuche sie durch Einwirkung von Metalloxyden oder Ammoniak zu ent-

1) 1. c. 
schwefeln, selbst unter starkem Druck und bei sehr hoher Temperatur, fielen bis jetzt negativ aus.

Bei der Einwirkung von metallischem Quecksilber, Silber und Kupfer auf Aethylenharnstoff fand Schacht, dass hierbei Aethylenthioharnstoff-Metallverbindungen entstehen, welche sehr für die unsymmetrische Form des Aethylenthioharnstoffes sprechen. Chlorwasserstoff wirkt, wie Schacht und ich gefunden haben, auf Aethylensulfoharnstoff nicht ein. Erst bei hoher Temperatur und starkem Druck tritt partielle Spaltung in Aethylendiamin und Schwefelwasserstoff ein. Ebenso verhălt sich konzentrierte Schwefelsäure. Auch Schwefelchlorür und Schwefelchlorid greifen, wie ich beobachtete, denselben nicht oder nur sebr schwer an.

Ich habe nun neue Entschwetelungsversuche mit dem Aethylenthioharnstoff angestellt, und es ist mir in der That gelungen, den entsprechenden Aethylenharnstoff, wenn auch in geringer Menge aus den Reaktionsprodukten $\mathrm{zu}$ isolieren. Derselbe entsteht nämlich durch Einwirkung von frisch gefälltem und ganz neutral reagierendem Queck. silberoxyd auf diesen Thioharnstoff.

Zur Darstellung wurden $8 \mathrm{~g}$ Aethylensulfoharnstoff in $200 \mathrm{~g}$ Wasser gelöst, die Lösung mit der berechneten Menge des angegebenen Quecksilberoxydes versetzt - auf 1 Molekül Harnstoff $=1$ Molekül $\mathrm{HgO}$ - und das Gemisch unter häufigem Umschütteln einige Zeit auf dem Wasserbade erwärmt. Schwärzung des Quecksilbers zeigt hierbei bald die Verwandlung desselben in das Sulfid an. Das klare farblose Filtrat reagierte stark alkalisch und war vollkommen quecksilberfrei. Dasselbe wurde auf dem Wasserbade zur Trockne verdampft, wobei schliesslich ein rötlichweisser, zäher, der angewandten Harnstoffmenge entsprechender, stark hygroskopischer Rückstand resultierte, in welchem irgend welche krystallinische Ausscheidungen nicht beobachtet wurden. Dieser in Wasser äusserst leicht lösliche und völlig schwefelfreie Rückstand wurde mit stark verdünnter Salzsäure bis zur schwach sauren Reaktion versetzt, wobei sich Kohlensäurebläschen entwickelten - ein Zeichen, dass selbst bei Anwendung von gănzlich alkalifreiem Quecksilberoxyd der Aethylenthioharnstoff partiell in Aethylendiamin hydrolysiert wird. - Die schwach saure Lösung wurde mit 1/10 Normal-Na.pikratLösung im Ueberschuss versetzt, wodurch sofort ein starker voluminöser Niederschlag entstand, welchen ich mit heissem Wasser behandelte. Ungelöst blieb hierbei der grössere Teil, welcher sich bei näherer Untersuchung als ein Gemisch verschiedener Körper erwies. In Lösung aber ging ein Pikrat, welches durch Konzentration bis auf etwa ein Drittel herauskrystallisierte. Behufs Elementarbestimmung wurde dieses Pikıat aus heissem Alkohol umkrystallisiert, worin es leicht 
löslich ist. Beim Abkühlen fällt es als ein mikrokrystallinisches Pulver aus, welches bei 207-209 ${ }^{\circ}$ unter Zersetzang schmilzt. Dieses Pikrat ist gänzlich schwefelfrei und erweist sich, wie die Analyse zeigt, als das pikrinsaure Salz des Aethylenthioharnstoffes:<smiles>O=C([O-])OCCCNC(=O)O[Na]</smiles>

Die Ausbente ist nur gering.

Kohlenstoff - und Wasserst of fbestimmung. 0,1596 g Substanz ergaben $0,2008 \mathrm{~g} \mathrm{CO}_{2}+0,0481 \mathrm{~g} \mathrm{H}_{2} \mathrm{O}$.

Stickstoff bestimmang. 0,1095 g Substanz lieferten $21,4 \mathrm{ccm} \mathrm{N}$, Bar. $762,0 \mathrm{~mm}$, Temp. 21,50 .

\begin{tabular}{|c|c|}
\hline Gefunden: & Berechnet für $\mathrm{C}_{9} \mathrm{H}_{9} \mathrm{~N}_{5} \mathrm{O}_{8}$ : \\
\hline C $34,31 \%$ & $34,28 \%$ \\
\hline H $\quad 3,38_{n}$ & $2,85 n$ \\
\hline $\mathrm{N} 22,31$ n & 22,22, \\
\hline
\end{tabular}

Interessant ist weiter das Verhalten des Aethylenthioharnstoffes bei Behandlung desselben mit Quecksilberoxyd in schwach alkalischer Lösung. Bei der Einwirkung von frisch gefälltem, aber noch etwas freies Alkali enthaltendem Quecksilberoxyd anf Aethylensulfoharnstoff in wässeriger Lösung tritt, wie ich beobachtete, völlige Spaltung desselben in Aethylendiamin, Schwefelwasserstoff und Kohlengäure ein nach der Gleichung:

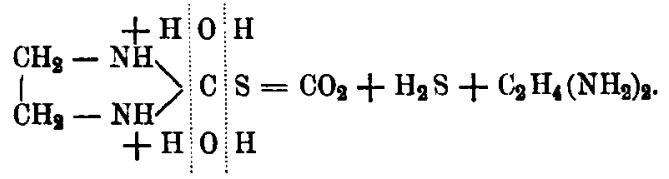

Der hierbei entstehende Schwefelwasserstoff verwandelt das Quecksilberoxyd in das Sulfid. Die Kohlensäure liefert mit dem treien Aethylendiamin das entsprechende Karbonat. Infolgedessen erklärt sich auch leicht die starke Gasentwickelung beim Hinzufügen von Säuren zu dem sirupartigen Abdampfrückstand.

Keine Spur des analogen schwefelfreien Harnstoffes konnte ich in dem Reaktionsgemisch feststellen. Der Thioharnstoff war total hydrolysiert.

Zum Nachweise, dass in diesem Abdampfrückstande fast nur Aethylendiamin vorhanden war, wurde aus demselben das salzsaure und pikrinsaure Salz, ferner das Dibenzoylderivat des Aethylendiamins dargestelit. Es zeigte sich hierbei, dass fast quantitativ der chemische Vorgang in der oben angegebenen Weise verlaufen war. 